\title{
MECHANICAL RELATIONSHIPS BETWEEN THE FIBER-LAMINATION METHODS AND THE STRUCTURAL FUNCTIONS OF ORYCTES RHINOCEROS HORNS
}

\author{
MEHANSKE POVEZAVE MED METODAMI LAMINACIJE \\ VLAKEN IN STRUKTURNIMI FUNKCIJAMI ROŽIČKA HROŠČA \\ NOSOROŽCA
}

\author{
Caiqi Zhao ${ }^{1}$, Shengchen $\mathrm{Du}^{1}$, Jinxiang Chen ${ }^{1 *, 2}$, Wanyong Tuo ${ }^{3}$, Mengye $\mathrm{Xu}^{1}$ \\ ${ }^{1}$ Key Laboratory of Concrete and Prestressed Concrete Structures of the Ministry of Education, Southeast University, 2\#, Southeast University \\ Road, Nanjing 211189, China \\ ${ }^{2}$ Department of Mechanical and Biofunctional Systems, Institute of Industrial Science, The University of Tokyo, 4-6-1 Komaba, Meguro-ku, \\ Tokyo 153-8505, Japan \\ ${ }^{3}$ School of Civil and Architectural Engineering, Anyang Institute of Technology, 73\#, Huanghe Avenue, Anyang, 455000, China
}

Prejem rokopisa - received: 2018-06-10; sprejem za objavo - accepted for publication: 2018-09-06

doi:10.17222/mit.2018.119

\begin{abstract}
To learn about the fiber-lamination design methods of light-weighted cylindrical composites, this study investigates the relationships between the exoskeleton of Oryctes Rhinoceros horns and their structural functions: 1) The odd and even numbered exterior layers of the fibers of the horn are oriented at $20^{\circ}$ and $150^{\circ}$, respectively, and the change of the fiber angles outside-in suits the mechanical needs of horns; 2) O. Rhinoceros horn has a flat top cross-section with a mellow root, which increases the bending performance of the root and can make the top thrust easily into trees. 3) The maximum average orientation degree of the back is 0.93, which is beneficial for the tensile properties in the y-direction. By comparison, the fibers in the front are oriented primarily in the $\mathrm{x}$-direction, which is suitable for resisting horizontal forces.

Keywords: Oryctes Rhinoceros, light-weighted cylindrical structure, orientation degree, fiber distribution
\end{abstract}

Avtorji so raziskovali metode oblikovanja laminacije vlaken lahkih cilindričnih kompozitov. Pri tem so preučevali povezavo med zunanjim skeletom rožička azijskega hrošča nosorožca in njegovimi strukturnimi funkcijami: 1) neparne in parne zunanje plasti vlaken hroščevega rožička imajo $20^{\circ} \mathrm{oz} .150^{\circ}$ orientacijo in sprememba nagiba zunanjih vlaken rožička je prilagojena njegovim potrebam, 2) rožiček hrošča nosorožca ima ploščat presek z mehkim korenom, ki omogoča njegovo krivljenje in enostavno prebadanje skorje dreves, 3) maksimalna povprečna stopnja orientacije zadka je 0,93, kar je ugodno s stališča natezne trdnosti v vertikalni smeri (y). Za primerjavo: prednja vlakna potekajo predvsem v horizontalni smeri $(\mathrm{x})$, kar omogoča prenašanje horizontalnih obremenitev.

Ključne besede: hrošč nosorožec (Oryctes rhinoceros), cilindrične strukture z majhno maso, stopnja orientacije, porazdelitev vlaken

\section{INTRODUCTION}

A lightweight body is required for beetles to fly. 1,2 The horn and the forewings must be high-strength materials ${ }^{3,4}$ to protect the body. Because the horn serves as the primary weapon ${ }^{5}$ and feeding tool, ${ }^{6}$ it must have better mechanical performance. Therefore, the beetle's horn, similar to the beetle's forewing, should be a lightweight material with a high strength, and is a composite of protein and fiber. ${ }^{7-11}$ Fiber-lamination structures in beetle shells, ${ }^{12-14}$ similar to those of fiber-reinforced composites, were first reported in the middle of the $19^{\text {th }}$ century. ${ }^{15}$ Double-helix lamination structures are prevalent in the exoskeletons of arthropods (e.g., beetles). ${ }^{12}$ Zelanzny and Neville (1972) ${ }^{16}$ researched the lamination structure of arthropod horns in detail, and determined the orientation angles of fibers from three parts of $O$. Rhinoceros. These authors' research also demonstrated

*Corresponding author e-mail:

chenjpaper@yahoo.co.jp that the lamination angles of the fibers found in the same parts of the same beetle are sufficiently consistent to conduct a universal data analysis. Hepburn and Ball ${ }^{13}$ reported in 1973 that fiber layers are interconnected by unique inter- and intra-ply cross-links that provide shearand crack-propagation resistance. The beetle's shell has isotropic properties as a result of its inherently tough anisotropic fibrous structure. Chen et al. ${ }^{17}$ conducted tensile tests to show that the non-equiangular laminations in the elytra of Trypoxylus Dichotomus cause two types of fracture (fiber crack and fiber bridge) and its failure mode is consistent with that of the non-equiangular lamination methods of elytra. The tensile crack strength in different directions is consistent with the average orientation degree $\eta$ in the corresponding direction. ${ }^{17}$ Arrow, Caro et al. investigated the shapes of beetle horns, ${ }^{18,19}$ and in 2014, McCullough ${ }^{5}$ demonstrated the constant relationship between the cross-sectional shapes of the horn and the mechanical characteristics of the horns by comparing three species of rhinoceros beetles. 
This study revealed that the beetles use their horns as different types of weapons for fighting, and under tensile, bending and torsion forces, beetle horns show the best performance corresponding to the specific form of fighting. Lee et al..$^{20}$ proposed an in-situ manipulation/ test method in a focused ion beam for characterizing the micromechanical properties of beetle horn shell.

However, there are few reports regarding the relationship between fiber-lamination methods, the cross-sectional shapes of the horns and the mechanical properties. Thus, based on previous anatomic reports of the fiberlamination structures of $O$. Rhinoceros horns, this study investigated the fiber-lamination methods, the cross-sectional structure of the horns and the mechanical performance. Such a study will provide valuable information for the development of light-weighted cylindrical fiber composites with similar functions.

\section{EXPERIMENTAL PART}

Observation of the cross-sectional shape: The $O$. Rhinoceros specimens were purchased and mailed from the Hainan province in China. After the natural deaths of the beetles, the horns were removed and cut into three parts from the root to the top with single-side slices. The cross-sections were then photographed with a camera.

Arrangement method of the lamination fibers in the horn in exoskeletons: To reduce costs and redundancy, this paper conducted further research, making full use of the published research ${ }^{16}$ of predecessors who have more professional knowledge of entomology and skills than the authors. Therefore, in this paper, the fiber-lamination data for the $O$. Rhinoceros horn is based on a paper published by Zelazny and Neville in $1972 .{ }^{16}$ The abbreviations A34, B34 and C29 are used to represent the layered structures of three different regions of the back, side and front of the beetle horn, respectively, where the numbers refer to the number of laminations (Figures 1a to $1 \mathrm{c})$. The angle of the laminations, $\beta$, is rotated in an anti-clockwise direction with the positive direction of the $y$-axis (the anatomical axis of the horn) as the starting axis (Figure 1).
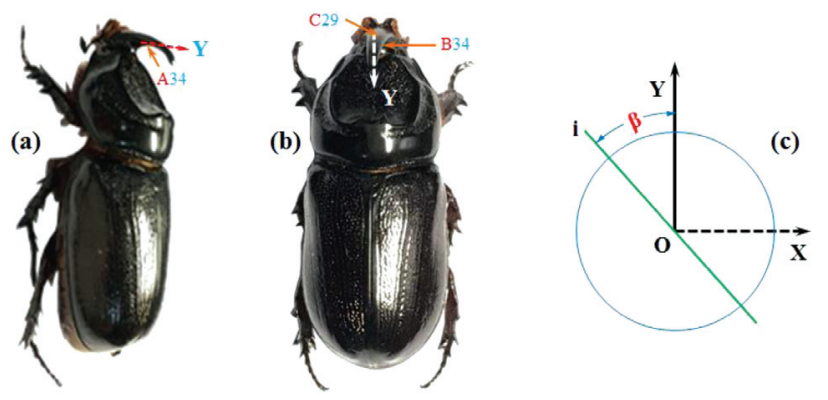

Figure 1: Reference system for the lamination angles and the schematic diagram of the position of the data source: a) side view, b) top view of the back, c) the angle reference coordinates
The average orientation degree, $\eta$, is used to describe the fiber distribution degree for different lamination methods in different directions, and is defined as follows: ${ }^{21}$

$$
\eta=\frac{1}{n} \sum_{i=1}^{n} \cos ^{2}\left(\beta_{\mathrm{t}}-\omega\right)
$$

where $\eta$ is the average orientation degree function of the lamination method, $n$ is the number of laminations, $i$ is the serial number of fibers in layer $i$, which increases in turn from the surface to the interior of the beetles, $\beta_{i}$ is the orientation angle in layer $i$, and $\omega$ is an independent variable that rotates in the anti-clockwise direction with the positive direction of the $y$-axis as the starting axis.

The average orientation degree function, $\eta(\omega)$, was calculated by substituting the angle value for each lamination method into the above equation, which represents the concentration of the lamination fibers in any direction, $\omega$. The experimental results of J. X. Chen et al. showed that the greater the average orientation degree in a certain direction is, the higher the concentration of fibers is, which indicates that in this direction, the mechanical properties of the fibers along the long axis dominate, resulting in a higher tensile strength and improved mechanical properties. ${ }^{17}$ Thus, the mechanical properties of different fiber-lamination structures can be analyzed.

\section{RESULTS AND DISCUSSION}

\subsection{Graphics of lamination methods in each position and their characteristics analysis}

The fiber-lamination methods in the three different parts of the back (A34), side (B34) and front (C29) of the $O$. Rhinoceros horn are shown in Figure 2. Figure 2a shows the results that the orientation angles of the lamination fibers are arranged separately in the odd and even numbered layers; Figure $2 \mathbf{b}$ shows the intersection angle between adjacent layers. To have a more intuitive impression of the fiber lamination, Figure $2 c$ shows a schematic line diagram of the fiber orientation angle for each layer. Figures $\mathbf{2 a}$ and $\mathbf{2 b}$ show that the non-equiangular lamination method is used in the three parts. And they have a common characteristic: the angles of the odd or even numbered layers (referred to as the "outer layers") of the first third of each part from the surface are similar (Figure 2a, $\Delta$, and o). The variation of the angles is also similar (Figure $\mathbf{2 b}, \mathrm{cp}_{1}-\mathrm{cp}_{2}$ ). That is, the fiber orientation angle is approximately $20^{\circ}$ for the odd numbered layers and approximately $155^{\circ}$ for the even numbered layers. This characteristic is shown in Figure 2c, where the odd and even numbered layers in the outer layers (Figure 2c, the black solid and dashed lines) are distributed on both sides of the y-axis, forming an " $\mathrm{X}$ "-shaped distribution between the " $\mathrm{X}$ " and "O" in Figure 2c. For convenience, the common design technique for the outer layer of the $O$. Rhinoceros horn is referred to as the "weak symmetrical X-shaped" design 

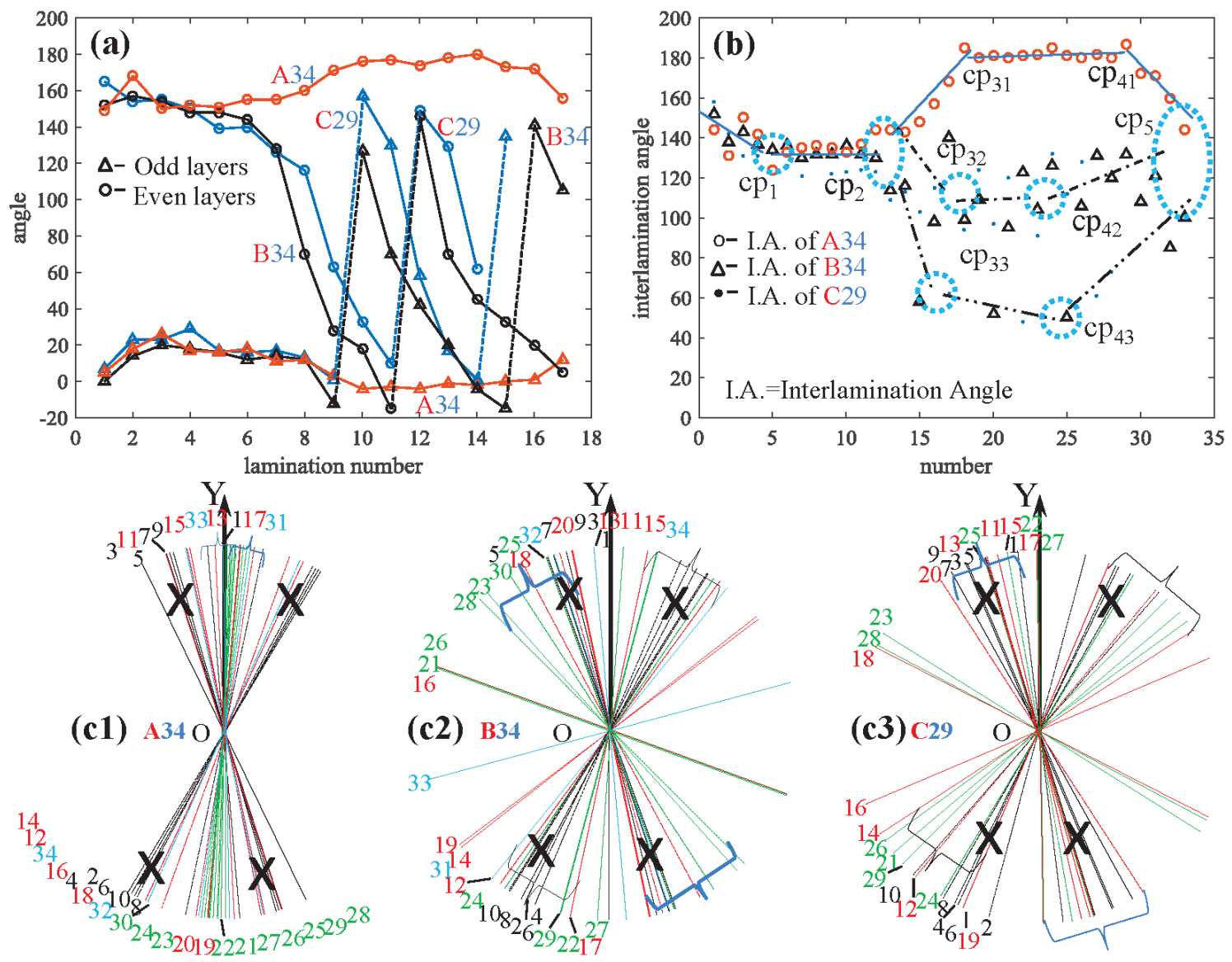

Figure 2: Fiber-lamination methods in three different parts of the O. Rhinoceros horn. a) Arrangement of the odd and even numbered layers, b) the intersection angle of the fibers between two adjacent layers, c) schematic line diagrams of the fiber orientation. The fibers (orientations) marked with $\mathrm{X}$ and the brace in the figure are the ones forming an X-or Y-shaped distribution. The data for the fiber lamination were reported by Zelazny and Neville. ${ }^{16}$

method in this paper ("weak symmetry" indicates that the odd and even numbered layers of the outer layer in Figure 2c are not perfectly symmetric about the y-axis).

The characteristics of the fiber-lamination methods in the inner two-thirds layers (referred to as the "middle and inner layers") were examined. Figure 2 shows that the back, side and front parts of the horn have different designs. For the odd and even numbered layers on the back of the horn, a design with upper-lower open type, inward buckling, and small changes in the orientation angle of the fibers is adopted (Figure 2a, solid line, A34). The intersection angle adopts an " $\vec{n} "$-shaped path (Figure 2b, $\mathrm{cp}_{2}-\mathrm{cp}_{31}-\mathrm{cp}_{41}-\mathrm{cp}_{5}$ ). The upper arrow indicates that the distribution is centered about the $y$-axis (Figure 2c1, the brace). However, Figure 2a shows that because the angles of the odd and even numbered layers in the

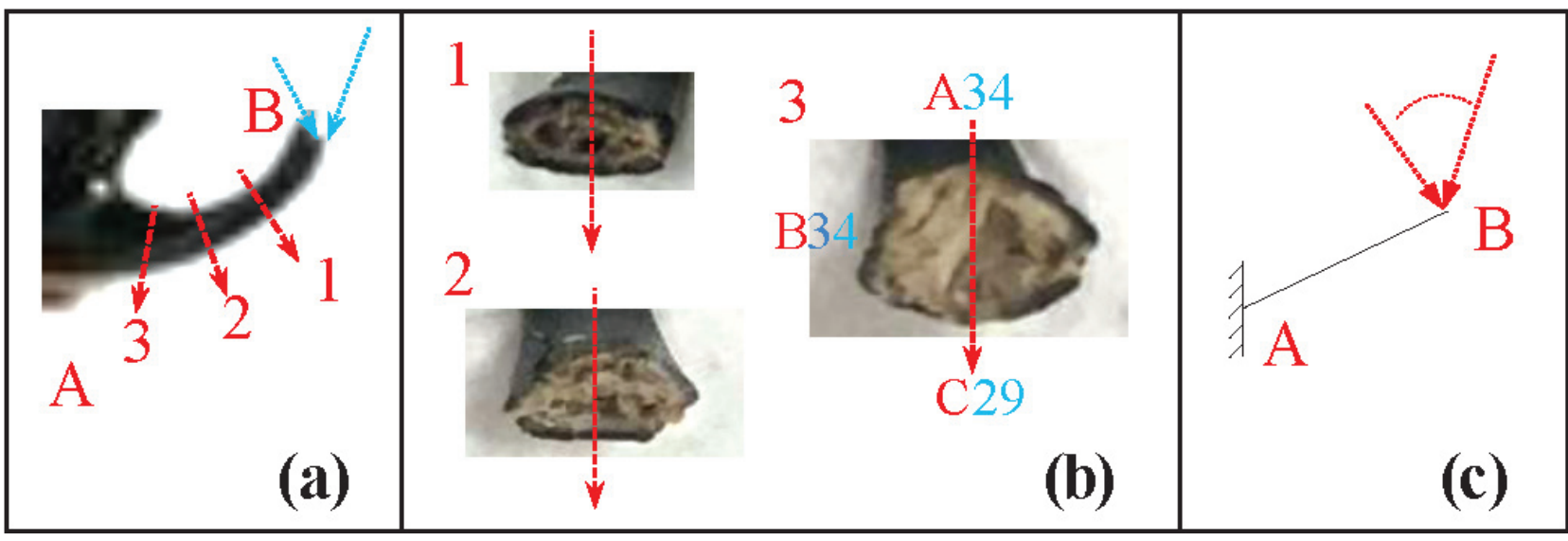

Figure 3: Photographs of $O$. Rhinoceros horn. a) Horn, b) cross-sections, and c) the schematic diagrams of the simplified mechanical model 


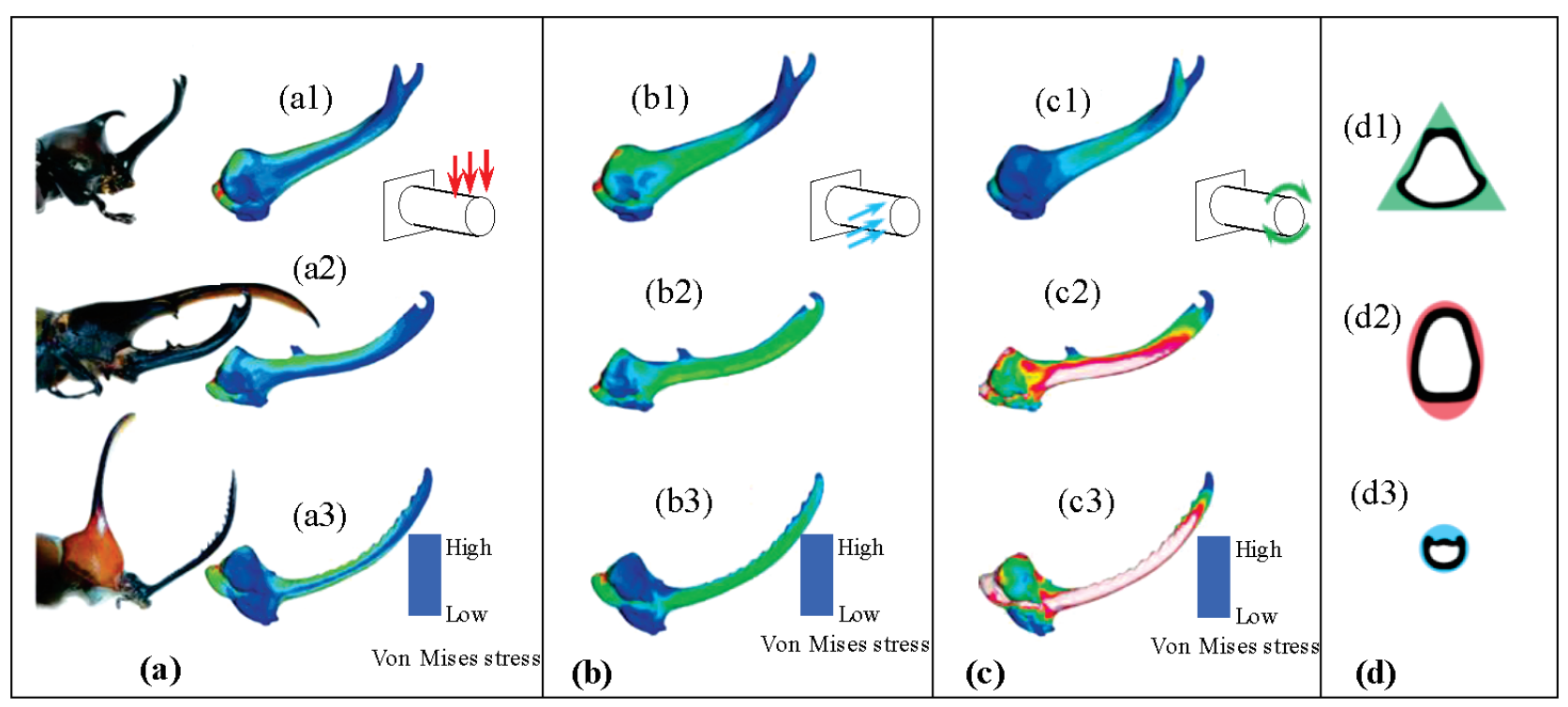

Figure 4: Von Mises stress distributions of the horn of T. Dichotomus, D. Hercules and G. Porteris under different directional forces. a) Vertical force, b) horizontal force, c) torsion and d) schematic diagrams of the cross-sections of the three beetles' horns. The data were reported by McCullough, Tobalske, and Emlen. (Reproduced from ${ }^{5}$, with permission from [PNAS])

middle and inner layers are similar to those of their respective outer layers, these fibers form an X-shaped design that overlaps with the $\mathrm{X}$-shaped distribution in the outer layer, although those with this arrangement are not many. Referring to Figure 2c1, the design for the back part is referred to as the "XY"-shaped design. The odd and even numbered layers on the side and front adopt a diminishing design, and when the fiber orientation angle drops to 0, it continues into the next cycle (Figure 2a, B34 and C29). This design is depicted as the " $\overline{\bar{u}} "$-shaped path on the fiber angle. The two points added at the top of the short line represent the dense fibers with a certain fluctuation in the angle (Figure $\mathbf{2 b}, \mathrm{cp}_{2}-\mathrm{cp}_{32}-\mathrm{cp}_{43}-\mathrm{cp}_{5}$ ). Additionally, the horn has an X-shaped distribution with a larger dispersion and overlap with the X-shaped fibers in the outer layer (Figures $\mathbf{2 c 2}$ and $\mathbf{2 c 3}$, the line segment shown in the brace). The " $u$ " shape represents sparsely distributed fibers (Figure $\mathbf{2 b}, \mathrm{cp}_{2}-\mathrm{cp}_{33}-\mathrm{cp}_{43}-\mathrm{cp}_{5}$ ). These fibers are between the " $\mathrm{X}$ " shapes of the middle and inner layers and form the second " $\mathrm{X}$ " -shaped fiber distribution in the middle and inner layers. Therefore, this design is referred to as the "XX"-shaped design in this paper.

Thus, comprehensively considering the design of the outer, middle and inner layers, the back of the horn has the XY-shaped design, while the side and the front have the XX-shaped design. Among them, the outer layers only adopt the $\mathrm{X}$-shaped design, while the middle-inner layers also have the $\mathrm{X}$-shaped design, echoing with the outer layers. The back has the Y-shaped design, which strengthens one direction of the horn, and the side and the front have the second $\mathrm{X}$-shaped design with the fibers between the former X-shaped ones.

\subsection{Analysis of the structural characteristics of the horn cross-section and its biological significance}

The cross-sectional shapes of the three parts (Figure 3a) of the $O$. Rhinoceros horn are shown in Figure $\mathbf{3 b}$. For comparison, the horns of three rhinoceros beetles studied by McCullough, ${ }^{5}$ the results of a finite-element analysis under different loading conditions and the structural schematic diagrams of their cross-sections are shown in Figure 4. As shown in Figures 3a and $\mathbf{3 b}$, the top cross-section (no. 3) of the horn is flat and the root (no. 3) is rounded and plump. It is very likely that the loading direction of the top end of the horn can change within a certain range, as indicated by the two arrows shown in Figure 3c, and it may be along the horizontal axis. Figure 4 shows that compared to the cross-sectional shape of the three beetles studied by McCullough et al., ${ }^{5}$ the cross-sectional shape at the root of the $O$. Rhinoceros horn is between that of T. Dichotomus and Dynastes Hercules and is flatter than that of D. Hercules. The cross-sectional structural characteristics of the $O$. Rhinoceros horn and their biological significance are discussed below.

It has been reported that $O$. Rhinoceros primarily uses its horn to feed by destroying trees. When feeding, the beetle stabs its horn into the plant fiber, opens a hole, and then bites the plant fiber or sucks the plant juice. ${ }^{6,22}$ Based on the shapes of the horns and the possible movements used to dig holes, it is conceivable that the left-right actions and pre-post swings of the $O$. Rhinoceros horn will expand the hole to improve the feeding efficiency. The long axis of the cross-section of the $O$. Rhinoceros horn is perpendicular to the anatomical axis of the torso, rather than parallel, even at the root. These structural characteristics bring about a better tolerance 
for lateral (horizontal) forces compared to the structures of the T. Dichotomus and the other two beetles (Figure 4a). ${ }^{5}$ The cross-sectional shape of the horn is longer in the left and right directions and is more suitable to withstand the force in the left and right directions, i.e., its structure is very suitable for expanding holes in horizontal directions. In particular, the end of the horn (Figure 3, cross-section no. 3) is flat, and the contact area with the plant is small, which helps with punctures. When regarded as the weapon in a combat, the end of the horn functions similarly to a knife. For the horn of Golofa Porteris, the combat mode is consistent with the characteristics of a good tolerance for lateral horizontal forces (Figure 4b2). However, the cross-sectional structure is still characterized by the left and right directions as the long axis at the root of the O. Rhinoceros horn. This structure ensures an optimized mechanical property in each part of the horn structure by improving the bending ability.

Of course, the structure of the O. Rhinoceros horn is similar to those of T. Dichotomus and the other two beetle species (Figure 4a) ${ }^{5}$ in one aspect as well. That is, when subjected to vertical forces, it also has such a good bending resistance that the beetle can insert or cut into plant fibers or pry with the flat structure of cross-section no. 3 using an upward motion when subjected to downward forces, as shown in Figures $\mathbf{4 a}$ and $\mathbf{4 c}$, because of its rounded cross-sections at the root (the moments of inertias of the major and minor axes are large) and curving horns. Based on the structure and mechanical characteristics under an applied force of the beetle horns, prying or reaming behaviors are also consistent with the characteristics of a cantilever beam. Figure $\mathbf{4 c}$ shows the simplified mechanical model and stress distributions. Figure 4 indicates that the rounded and plump crosssectional shape near the root significantly increases the moment of inertia and improves the bending performance, which is beneficial when the beetle reams holes backwards using the curving structures of the horn.

Thus, although the cross-sections at the root of the $O$. Rhinoceros horn are similar to those of the three beetles studied by McCullough et al., ${ }^{5}$ they have some unique characteristics. Such a cross-sectional structure could inspire a functional structure that can bear both a downward force and lateral forces.

\subsection{Fiber-lamination methods and comprehensive analysis}

In this section the fiber-lamination design methods are explored on the basis of the cross-sectional structural characteristics and corresponding mechanical properties of the $O$. Rhinoceros horn, as described above.

Figure 5a shows the fiber orientation degree curve, $\eta$, of the $O$. Rhinoceros horn. Figure 5b shows a schematic diagram of the three parts of each cross-section. As shown in Figure 5a, the three curves of the fiber orientation degrees have maximum values at $0^{\circ}\left(180^{\circ}\right)$, i.e., nearly along the $y$-axis direction: the specific angles corresponding to the maximum values of the curves, $\omega_{\max }$, are $\mathrm{X}=3^{\circ}, 0^{\circ}$ and $6^{\circ}$, respectively. The maximum value of the three deviations from the $y$-axis is only $6^{\circ}$, which indicates that the primary axes of the fiber laminations of three parts are along the y-direction. In terms of fiber-lamination methods, this correspondence originates from the "Y-shaped" fiber distribution as well as the equivalent effect of a "weak symmetric X-shaped" fiber distribution along both sides of the y-axis. Ingeniously, although different fiber-lamination angles are used in the middle and interior fibers of each of the three parts (Figures $\mathbf{2 a}$ and $\mathbf{2 b}$ ), the same effect is achieved. The maximum values of the fiber orientation degree, $\eta$, all occur near the $y$-axis because the horn can
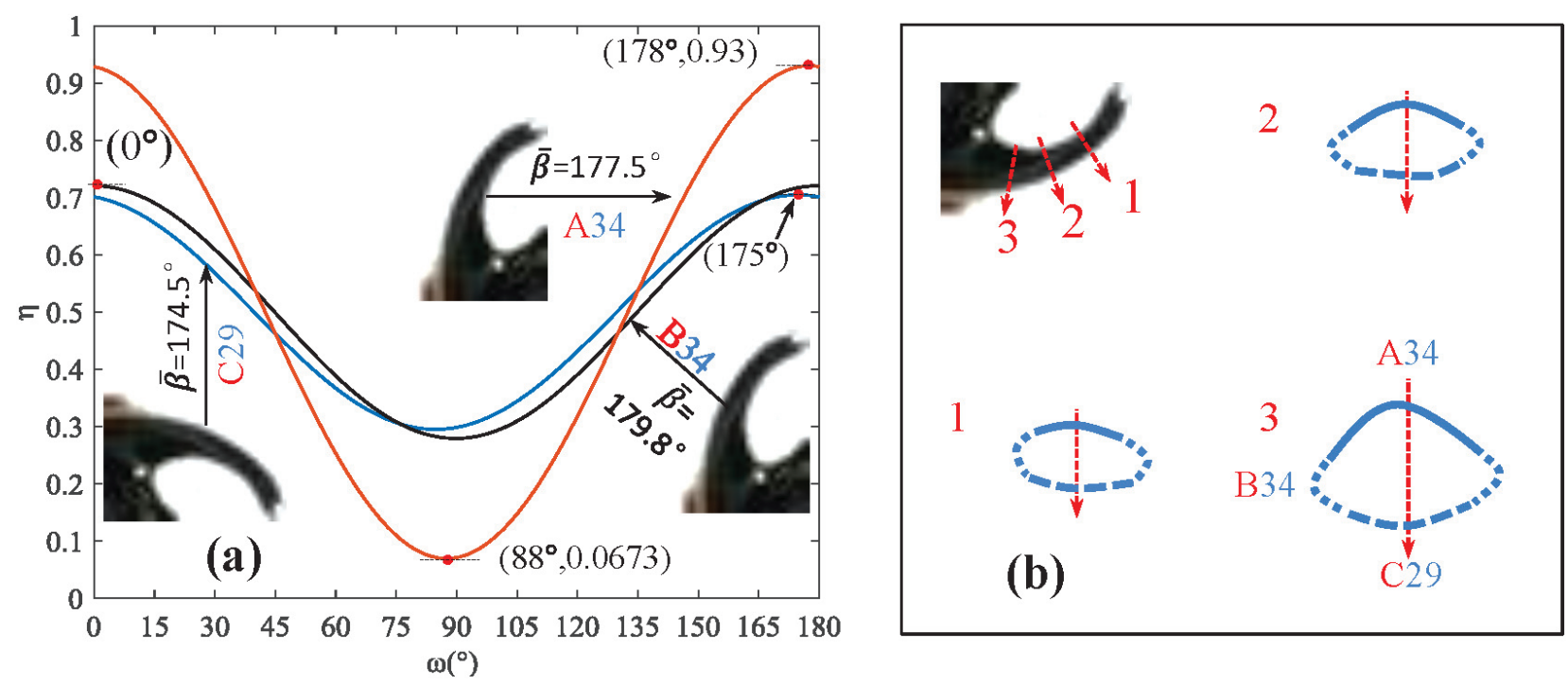

Figure 5: a) Plots of the average fiber orientation angles in the O. Rhinoceros horn and b) a schematic diagram of the three parts of each cross-section 
be simplified as a rod-like structure (Figure 3c, upper part of Figure $\mathbf{5 b}$ ) and the highest strength is required in the y-axis direction when the beetle horn bears common forces. Second, the maximum values of $\eta$ are significantly different in each part. The $\eta_{\max }$ of the back A34 is 0.93 , and the concentration degree of the fiber is extremely high, but those of the side and the front are much weaker $\left(\eta_{\max }\right.$ is approximately 0.70$)$. Based on Figure $\mathbf{4 c}$ and Figure $\mathbf{5 b}$, when the horn bears the load, the bending moment at the root reaches the maximum value, and the area at the back part of the root is smaller than that of the front part of the root (Figure 5b3, wide solid line, wide dashed line). The back part, i.e., the inner concave area in Figure 5b (Figure 5, the solid line in each cross-section) is in tension, so $\eta_{\max }=0.93$ (nearly 1) on the back part, and the number of fiber laminations is also the maximum (34 layers). That is to say, almost all of the fibers on the back part are distributed along the $y$-axis, which is most beneficial to resist tension in the $\mathbf{y}$-direction. Whereas the front area (Figure 5b, wide dashed line) is under compression, this part needs to bear the horizontal force of expansion in the lateral directions as well, so there are certain strength requirements for the $\mathrm{x}$-direction. From Figure 2c, in the first quadrant, the intersection angle between the fiber direction angle and the $\mathrm{y}$-axis is within $-25^{\circ}$ (Figure 2c1) on the back side and $15^{\circ}$ to $45^{\circ}$ on the front side (Figure $2 \mathbf{c 3}$ ), indicating that the fibers on the front side are oriented more closely to the $\mathrm{x}$-axis than those on the back side. Thus, it is more advantageous to defend attacks from the left and right directions, and enhance the stability in the y-axis direction under compression. In addition, the area of the front side of the root is the largest, so the minimum number of fiber laminations is used to save material. For the side part (Figure 5b, left and right side, dotted line), the area near the back is in tension, and the one near the front is in compression. Therefore, it has both compressive and tensile zones, which are regarded as the transition types of the back and front sides, and it has the same number of fiber laminations as the back side, but the curve of its fiber orientation degree (i.e., the fiber distribution pattern) is almost identical to that of the front side. Thus, it has an organic transition from the back side to the front side.

Therefore, the fibers in the $O$. Rhinoceros horn are arranged in a non-equiangular lamination method, and different designs and numbers of fiber laminations are used on the back, side and front of the horn. The macroscopic curving shape and the change of the cross-sectional shapes from the top to the bottom of the horn, the ability to move in all four directions and the reasonable distribution of material throughout the horn help protect the $O$. Rhinoceros, while maintaining a balance between high strength and weight reduction. This work, as the initial research of this study group on the horn, only made a qualitative description of these influencing factors and their effects, and a quantitative analysis related to fiber lamination and its mechanical properties will be further studied in the future.

\section{CONCLUSIONS}

By comparatively analyzing the fiber-lamination methods, cross-sections and mechanical characteristics of $O$. Rhinoceros horns, this paper discussed the relationship between the exoskeleton lamination of $O$. Rhinoceros and its mechanical properties, and the following results were obtained:

1) Non-equiangular fiber-lamination methods are used in all parts of the $O$. Rhinoceros horn, and the odd and even numbered exterior layers of the fibers are oriented at $20^{\circ}$ and $150^{\circ}$, respectively, with respect to the $\mathrm{y}$-axis and they both have the "weak symmetric X-type" design. The fiber-lamination designs of the middle and interior fibers in the horn differ in different parts. The "XY-type" design that contains fibers in the middle of an $\mathrm{X}$-shaped distribution oriented along the $\mathrm{y}$-axis is present in the back part, whereas the "XX-type" design that contains fibers distributed densely and sparsely is present in both the side and front parts. These fiber-lamination methods satisfy the mechanical needs of the O. Rhinoceros horns when in use.

2) The top cross-section of the O. Rhinoceros horn is flat, and the root is mellow. These characteristics are suitable for digging into trees for feeding. The mellow, full cross-sectional shape at the root makes the cross-sections along the major and minor axes have a larger moment of inertia. The improved bending performance in the downward and lateral directions and the flat top structure are beneficial for thrusting easily into plant fibers to ream holes in many directions and improve the feeding efficiency. The cross-section of the O. Rhinoceros horn is similar to that of the three beetles studied by McCullough et al., ${ }^{5}$ but with its own unique characteristics, which will serve as an inspiration for designing composite structures with heading, cutting and reaming functionalities in the lateral directions.

3) For the three parts of the $O$. Rhinoceros horn, the principal axes of the fiber lamination are all along the y-axis due to the "Y-type" fiber distribution, as well as the equivalent effect on the "weak symmetric X-type" fiber distribution along both sides of the y-axis. When the horn bears a load, the bending moment at its root is greatest, and $\eta_{\max }$ is close to 1 . Thus, almost all of the fibers are oriented along the direction of the y-axis, which is beneficial for bearing tensile loads in the y-direction. Meanwhile, the front part of the horn bears loads applied from the left and right directions, and thus contains more fibers distributed along the $\mathrm{x}$-axis than the back part. Such a fiber distribution can more efficiently resist forces applied laterally and increases the stability under compression in the y-direction. Besides, the front part of the horn at the root has the largest area and the fiber-lamination number is minimal. The combination of 


\section{ZHAO et al.: MECHANICAL RELATIONSHIPS BETWEEN THE FIBER-LAMINATION METHODS AND ...}

the cross-sectional shape, the fiber-lamination methods and the number of fiber laminations provides the $O$. Rhinoceros horn with an optimal biological structure suitable for the mechanical requirements of digging for feeding or fighting, thus enhancing survival, and may serve as an inspiration for designing biomimetic, lightweighted cylindrical composite materials capable of withstanding similar forces.

\section{Acknowledgments}

This study was supported by the Natural Science Foundation of China under Grant no. 51578136.

\section{REFERENCES}

${ }^{1}$ N. F. Hadley, The arthropod cuticle, Sci. Am., 255 (1986), 104-112, doi:10.1038/scientificamerican0786-104

${ }^{2}$ J. Y. Sun, J. Tong, D. H. Chen, J. B. Lin, X. P. Liu, Y. M. Wang, Micro-tensile testing of the lightweight laminated structures of beetle elytra cuticle, Adv. Nat. Sci., 3 (2010), 225-234

${ }^{3}$ J. X. Chen, J. Xie, Z. S. Wu, E. M. Elbashiry, Y. Lu, Review of beetle forewing structures and their biomimetic applications in China: (I) On the structural colors and the vertical and horizontal crosssectional structures, Mater. Sci. Eng. C., 55 (2015), 605-619, doi:10.1016/j.msec.2015.05.064

${ }^{4}$ J. X. Chen, Q. Zu, G. Wu, J. Xie, W. Y. Tuo, Review of beetle forewing structures and their biomimetic applications in China: (II) On the three-dimensional structure, modeling and imitation, Mater Sci. Eng. C., 55 (2015), 620-633, doi:10.1016/j.msec.2015.04.045

${ }^{5}$ E. L. Mccullough, B. W. Tobalske, D. J. Emlen, Structural adaptations to diverse fighting styles in sexually selected weapons, PNAS., 111 (2014), 14484-14488, doi:10.1073/pnas.1409585111

${ }^{6} \mathrm{R}$. W. Doane, The rhinoceros beetle (Oryctes Rhinoceros L.) In Samoa, J. Econ. Entomol., 6 (1913), 437-442, doi:10.1093/jee/ 6.6.437

${ }^{7}$ C. T. Xiang, Mechanism of natural composite materials and composite materials research coleoptera insects bionic design - its gradual microstructure and mechanical behavior, Doctor Engineering Thesis, Chongqing University, Chongqing, China, 1994

${ }^{8}$ J. X. Chen, W. Y. Tuo, Z. S. Guo, L. L. Yan, The 3D lightweight structural characteristics of the beetle forewing, Mater. Sci. Eng. C., 71 (2017), 1347-1351, doi:10.1016/j.msec.2016.10.060
${ }^{9}$ J. X. Chen, X. M. Zhang, Y. Okabe, K. Saito, Z. S. Guo, L. C. Pan, The deformation mode and strengthening mechanism of compression in the beetle elytron plate, Mater. Des., 131 (2017), 481-486, doi:10.1016/j.matdes.2017.06.014

${ }^{10}$ X. M. Zhang, J. Xie, J. X. Chen, Y. Okabe, L. C. Pan, M. Y. Xu, The beetle elytron plate: a lightweight, high-strength and buffering functional-structural bionic material, Sci. Rep., 7 (2017), 4440-4447, doi:10.1038/s41598-017-03767-w

${ }^{11}$ J. X. Chen, M. Y. Xu, Z. S. Guo, X. D. Yu, Structural characteristics of the core layer and biomimetic model of the ladybug forewing, Micron., 101 (2017), 156-161, doi:10.1016/j.micron.2017.07.005

${ }^{12}$ A. C. Neville, B. M. Luke, A two-system model for chitin-protein complexes in insect cuticles, Tissue Cell., 1(1969), 689-707, doi:10.1016/S0040-8166(69)80041-8

${ }^{13}$ H. R. Hepburn, A. Ball, Structure and mechanical properties of beetle shells, J. Mater. Sci., 8 (1973), 618-623, doi:10.1007/ BF00561216

${ }^{14}$ Y. Bouligand, Twisted fibrous arrangements in biological materials and cholesteric mesophases, Tissue Cell., 4 (1972), 189-217, doi:10.1016/S0040-8166(72)80042-9

${ }^{15}$ H. Meyer, Über den Bau der Hornschale der Käfer, Arch. Anat. Physiol. Wissensch. Med. (Müllers Archiv), (1842), 12-16

${ }^{16}$ B. Zelazny, A. C. Neville, Quantitative studies on fibril orientation in beetle endocuticle, J. Insect. Physiol., 18 (1972), 2095-2099, doi:10.1016/0022-1910(72)90243-0

${ }^{17}$ J. X. Chen, M. Iwamot, Q. Q. Ni, K. Kurashiki, K. Saito, Laminated structure and its mechanical properties of the fore-wing of beetle, J. Soc. Mater. Sci., 50 (2001), 455-460, doi:10.2472/jsms.50.455

${ }^{18}$ G. Arrow, Horned Beetles: A study of the fantastic in nature, $1^{\text {st }}$ ed., Junk Publishers, The Hague, 1951, 68

${ }^{19}$ T. M. Caro, C. M. Graham, C. J. Stoner, M. M. Flores, Correlates of horn and antler shape in bovids and cervids, Behav. Ecol. Sociobiol., 55 (2003), 32-41, doi:10.1007/s00265-003-0672-6

${ }^{20}$ H. T. Lee, H. J. Kim, C. S. Kim, K. Gomi, M. Taya, S. Nomura, S. H. Ahn, Site-specific characterization of beetle horn shell with micromechanical bending test in focused ion beam system, Acta Biomater., 57 (2017), 395-403, doi:10.1016/j.actbio.2017.04.026

${ }^{21}$ E. Batschelet, Statistical methods for the analysis of problems in animal orientation and certain biological rhythms, $1^{\text {st }}$ ed., American Institute of Biological Sciences, Washington DC 1965, 10

${ }^{22}$ M. Schmaedick: Coconut Rhinoceros beetle. Pests and diseases of American Samoa, https://www.ctahr.hawaii.edu/adap/ASCC_Landgrant/Dr_Brooks/BrochureNo8.pdf, 27.08.2017 